\title{
Microssimulação da travessia de pedestres: coleta de dados para calibração de modelos
}

\author{
André Cademartori Jacobsen ${ }^{1}$ e Helena Beatriz Bettella Cybis ${ }^{2}$
}

\begin{abstract}
Resumo: A microssimulação de tráfego tem incorporado, cada vez mais, modelos que representam os pedestres e suas interações com veículos. A simulação de travessias de pedestres classicamente utiliza um modelo de aceitação de brechas, cujos parâmetros devem ser calibrados para cada situação. Este artigo apresenta a metodologia de coleta de dados desenvolvida para obtenção de valores de brechas frontais e traseiras com o objetivo de calibrar um modelo de travessias de pedestres codificado através do software VISSIM. O método utilizado permite a consideração de particularidades do processo de travessia de pedestres como, por exemplo, situações em que os pedestres atravessam fora da área sinalizada, ou iniciam a travessia enquanto o veículo ainda não liberou a faixa de tráfego. O processo de coleta é baseado em análise de imagens, que são transformadas e utilizadas para rastrear pedestres e veículos. A análise do conflito entre as rotas de veículos e pedestres resulta nos valores de brechas para calibração de modelos. A metodologia apresentada é aplicável a outros processos de coleta que envolvam análises de conflitos de tráfego.
\end{abstract}

Palavras-chave: pedestres, coleta de dados, aceitação de brechas

\begin{abstract}
The microsimulation of traffic is incorporating models to represent pedestrians and their interactions with vehicles. The pedestrian crossing simulation is typically based on gap acceptance models, whose parameters should be calibrated for each specific situation. This paper presents a data collection methodology developed to acquire values of front and rear gaps with the objective of calibrating a pedestrian crossing model coded in the VISSIM software. This method allows the analysis of important particularities of the pedestrian crossing process, as for instance, pedestrians crossing at unsignalized areas, or starting to cross before vehicles leave the traffic lane. The data collection process is based on the analysis of images, which are transformed and used to track the pedestrians and vehicles. As analysis of the conflict between vehicle and pedestrians' routes result on the gap values for the model calibration process. This methodology is applicable to other data collection processes that require traffic conflicts analysis.
\end{abstract}

Keywords: pedestrian, data collection, gap acceptance

\section{INTRODUÇÃO}

As interações entre pedestres e veículos são aspectos críticos em relação à segurança e atrasos. Os problemas de segurança são evidenciados pela severidade dos acidentes que envolvem os dois modos, frequentemente resultando em ferimentos graves e óbitos. Os atrasos são, muitas vezes, decorrentes de travessias mal projetadas que aumentam a variabilidade e tempo de viagem.

Estas interações têm recebido atenção especial de técnicos e desenvolvedores de softwares de simulação de tráfego. A engenharia de tráfego, que historicamente concentra maior atenção aos veículos motorizados, passou a considerar também os modos não motorizados. Neste cenário, surge uma demanda por modelos que representem o comportamento de pedestres e veículos com um nível de detalhamento compatível com os simuladores de tráfego.

$\mathrm{Na}$ modelagem de tráfego multimodal, o deslocamento dos veículos é simulado tradicionalmente por modelos de car-following e lane-changing, e os pedestres por um modelo de movimentação, como o de Forças Sociais utilizado pelo VISSIM (PTV, 2009), que é baseado em forças de a-

\footnotetext{
${ }^{1}$ André Cademartori Jacobsen, Laboratório de Sistemas de Transportes, Programa de Pós-Graduação em Engenharia de Produção, Universidade Federal do Rio Grande do Sul, Porto Alegre, RS, Brasil. (e-mail: andrecja@terra.com.br).

${ }^{2}$ Helena Beatriz Bettella Cybis, Laboratório de Sistemas de Transportes, Programa de Pós-Graduação em Engenharia de Produção, Universidade Federal do Rio Grande do Sul, Porto Alegre, RS, Brasil. (e-mail: helenabc@producao.ufrgs.br).
}

Manuscrito recebido em 29/4/2011 e aprovado para publicação em 7/7/2011. Este artigo é parte de TRANSPORTES v.19, n.2, 2011. ISSN: 2237-1346 (online). tração e repulsão entre pedestres e os elementos do ambiente. As interações, que ocorrem nas travessias, geralmente são representadas por um modelo de aceitação de brechas.

Este artigo apresenta a metodologia de coleta de dados desenvolvida para obter parâmetros para calibração do modelo de aceitação de brechas do VISSIM. Este software foi escolhido, dentre outros, por utilizar uma abordagem mais elaborada da interação entre veículos e pedestres. Neste modelo, as brechas são medidas em relação à área de conflito da travessia, e não entre veículos, como no caso tradicional, apresentado posteriormente neste artigo.

De maneira geral, assume-se que pedestres e veículos adotam comportamentos diferenciados, de acordo com o tipo de travessia: (i) semaforizadas, (ii) sinalizadas e (iii) não sinalizadas. Nas travessias semaforizadas, considera-se que não existe aceitação de brechas porque não ocorre interação entre veículos e pedestres. Nas travessias sinalizadas (e.g. faixas de segurança) a preferência é dos pedestres, e os veículos aceitam brechas entre eles. Nestes casos, a calibração dos parâmetros de aceitação de brechas requer uma coleta de dados, pois as brechas aceitas podem depender de fatores locais como fiscalização, número de faixas de tráfego, número de pedestres e faixa etária, etc. As situações em que veículos não obedecem à sinalização não serão analisadas, pois nos softwares de simulação pesquisados a sinalização da travessia é sempre obedecida.

Nas travessias não sinalizadas, os pedestres aceitam brechas no fluxo de veículos. A modelagem deste caso apresenta dificuldades adicionais, pois as características dos seus deslocamentos são diferentes. Blue e Adler (1999) destacam que pedestres não andam oficialmente em faixas, 
podem acelerar instantaneamente até sua velocidade máxima, tem menos preocupação com eventuais colisões em outros pedestres e podem andar em grupos, dentre outras diferenças. Isto implica, no caso de travessias, que eles podem iniciar a travessia repentinamente, mesmo que haja conflitos entre pedestres durante o percurso. Estas características implicam em uma maior complexidade na coleta de dados, especialmente nos casos em que os pedestres não aguardam o final da passagem do veículo para atravessar.

A metodologia para coleta de dados, independentemente do tipo de travessia, geralmente envolve coletas de imagens. As principais diferenças encontradas na literatura, portanto, são as variáveis e o método de extração de dados a partir das imagens. No método manual, a extração dos dados é feita por pesquisadores, que observam o vídeo, repetidamente, e anotam os tempos em que ocorrem eventos (e.g. chegada de veículos, início da travessia, etc.). No método semiautomático, são efetuadas marcações de posições dos objetos manualmente no vídeo, as coordenadas reais e os tempos são registrados automaticamente. No método automático, utilizam-se ferramentas de processamento de imagens e vídeos para identificar, classificar e rastrear objetos nos vídeos.

A metodologia proposta, classificada como semiautomática, foi desenvolvida para coletar dados de uma travessia não sinalizada. O procedimento consiste em (i) coletar as imagens, (ii) transformar as imagens, para identificar as posições reais dos objetos, (iii) rastrear os objetos (veículos e pedestres), marcando suas posições conforme instruções predefinidas, para obter uma rota, e (iv) processar os dados para obter os parâmetros desejados, que neste caso foram as brechas frontais e traseiras. Utilizar recursos do laboratório onde foi desenvolvido o estudo ou gratuitos foi um objetivo secundário da metodologia, que resultou no uso de uma filmadora convencional, softwares de domínio público (e.g. ImageJ) e softwares comerciais (Matlab).

Este artigo apresenta uma revisão dos modelos de aceitação de brechas tradicional e o do VISSIM (seção 2), os processos de coleta de dados utilizados na literatura (seção 3), a metodologia proposta (seção 4), resultados e discussão (seção 5) e considerações finais (seção 6).

\section{MODELOS DE ACEITAÇÃO DE BRECHAS}

A metodologia de coleta de dados proposta foi desenvolvida para calibrar o modelo de aceitação de brechas utilizado pelo VISSIM. Em uma revisão da literatura sobre travessias, no entanto, identifica-se que geralmente é utilizado o modelo tradicional. Neste caso, ambos os modelos são apresentados, com intuito de facilitar a compreensão dos processos de coleta de dados apresentados nos capítulos seguintes e justificar a escolha do modelo do VISSIM. Neste capítulo, os exemplos utilizados se referem às travessias não sinalizadas, em que os pedestres aceitam brechas.

$\mathrm{Na}$ aceitação de brechas tradicional, a brecha é o intervalo de tempo entre a passagem do para-choque dianteiro de um veículo e o do veículo seguinte, por um ponto de referência (TRB, 2000). A brecha crítica é o parâmetro único da travessia, que pode ser interpretado como o tempo mínimo aceito pelos pedestres para atravessar com segurança
(Fitzpatrick, 2006). Na prática, existem diferentes formas de estimar o valor da brecha crítica, sendo comum adotar o valor para o qual a probabilidade da brecha ser aceita ou rejeitada é igual. Analisando resultados de uma coleta de dados, este valor pode ser obtido graficamente, a partir das curvas de frequências acumuladas destas brechas, correspondendo ao ponto onde elas se cruzam. No entanto, o valor definido é uma média para todos pedestres, e características individuais (e.g. velocidade de caminhada) não são consideradas.

Nos modelos de simulação, em uma travessia não sinalizada, por exemplo, um pedestre aguardando na calçada estima brechas entre os sucessivos veículos, até que o valor seja maior que a brecha crítica, quando inicia a travessia. Neste caso, todos pedestres iniciam a travessia, pois o modelo é determinístico e a brecha crítica é comum a todos.

Na aceitação de brechas do VISSIM, os parâmetros utilizados são a brecha frontal, brecha traseira, visibilidade e a distância de parada adicional (PTV, 2009). A interação ocorre na área de conflitos, destacada na Figura 1, formada pela interseção das faixas de veículos e de pedestres. A brecha frontal é o intervalo mínimo entre a saída do veículo 1 da área de conflitos e o início da travessia. A brecha traseira é o intervalo mínimo aceitável entre a saída do pedestre, após concluir a travessia, e a chegada do próximo veículo. Adicionalmente, a visibilidade (v) é a distância a partir da qual o pedestre identifica o veículo e a distância adicional de parada (d) é a distância entre a área de espera e a área de conflito.

No VISSIM, ao chegar à travessia, o pedestre identifica se os veículos 1 e 2 (ilustrados na Figura 1) estão no intervalo visível. $\mathrm{O}$ pedestre realiza sucessivas estimativas da velocidade mínima necessária para conseguir realizar a travessia respeitando as brechas mínimas, até que seja inferior à sua velocidade de caminhada (máxima), quando a travessia é iniciada (PTV, 2009).

No modelo do VISSIM, com a decisão na travessia dependendo da velocidade individual do pedestre, o nível de detalhe está mais próximo do modelo de veículos. PTV (2009) destaca que, nas áreas de conflitos, eles são mutuamente conscientes da presença um do outro. Caso um pedestre erre a estimativa da velocidade ou um veículo fora do intervalo visível chegue à área de conflito antes de o pedestre concluir a travessia, os veículos reduzem a velocidade para evitar um acidente. Nos casos com múltiplas faixas, os pedestres aguardam brechas que permitam atravessar todas as faixas simultaneamente. Neste caso, quando o veículo chega à área de conflito durante a travessia, os pedestres param entre as faixas e aguardam uma nova brecha.

O processo de coleta de dados para calibração do modelo do VISSIM deve obter valores de brechas frontais e trasei-

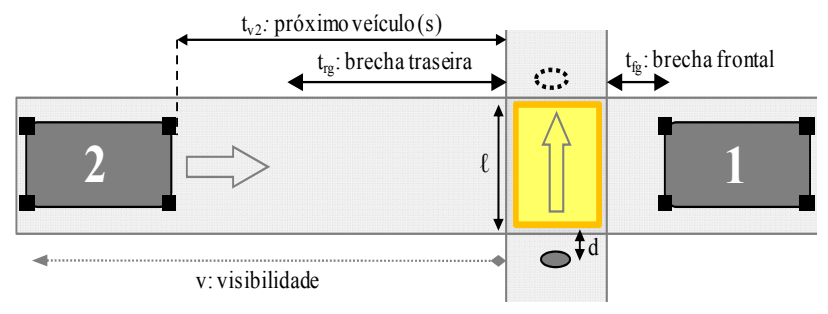

Figura 1. Parâmetros da aceitação de brechas do VISSIM 
ras. Estas brechas são medidas, diferentemente das brechas tradicionais, nos instantes em que o pedestre entra ou sai da área de conflito. Existem dois casos especiais em que a coleta de dados é dificultada: (i) em faixas de tráfego largas, em que os pedestres aguardam a brecha dentro da área de conflito e (ii) em vias com múltiplas faixas, em que as brechas devem ser medidas individualmente para cada faixa. Não é claro se, no primeiro caso, as brechas medidas devem ser consideradas em algum dos modelos, já que o comportamento pode não ser adequado para a segurança. No segundo caso, quantidade de dados extraídos pode exigir mais tempo de processamento, mas a validade do modelo de aceitação de brechas tradicional para simular a travessia de múltiplas faixas em nível microscópico deve ser analisada com cuidado. A necessidade de avaliar faixas de tráfego e as posições dos veículos e pedestres no processo de coleta das brechas é uma das justificativas para a utilização de um método de coleta semiautomático, como o proposto neste artigo.

\section{PROCESSOS DE COLETA DE DADOS}

A coleta de dados em pesquisas sobre a travessia de pedestres geralmente envolve coleta de imagens. Exceções são o estudo de aceitação de brechas apresentando vídeos aos pedestres, de Schmidt e Färber (2009), e o desenvolvimento de modelos de escolha do local de travessia, não apresentados neste artigo, que utilizam entrevistas, como o de Chu et al. (2004). Esse capítulo apresenta uma revisão dos processos de coleta de dados relatados na literatura, em que a extração de dados foi feita de forma automática, semiautomática e manual. Outras etapas da coleta de dados, como a coleta de imagens, são comuns a diversos trabalhos e não são apresentados neste estudo.

Existe um esforço pelo desenvolvimento de tecnologias de visão computacional, e ferramentas de processamento de vídeos e imagens, que permitam detectar e rastrear veículos e pedestres automaticamente nas filmagens. Para isso, são necessários algoritmos capazes de identificar, classificar e rastrear os objetos, mesmo em situações com oclusões e sombras. Uma das principais vantagens do processamento automático é a possibilidade de coletar dados por períodos mais extensos, já que manualmente esta tarefa pode ser considerada demorada e monótona.

Chae (2005) desenvolveu uma ferramenta (ITRE-mv) para processar os vídeos de travessias automaticamente, que detecta objetos rígidos (veículos) e não rígidos (pedestres). No processo de coleta de dados, em travessias nos acessos a rotatórias, o autor identificou limitações que tornam necessário rastrear manualmente alguns objetos. Recentemente, Ismail et al. (2009) desenvolveram uma ferramenta automática para rastrear pedestres e veículos e detectar eventos que possam conduzir a colisões, calculando indicadores de severidade dos conflitos. Os autores destacam que para utilizar a ferramenta em ambientes com fluxos maiores, no entanto, são necessários aperfeiçoamentos. $\mathrm{O}$ processo de coleta de dados, conforme se observa nas ilustrações do artigo, associou as posições dos objetos ao seu centro geométrico nas imagens identificadas. Esta simplificação não é adequada para a calibração de modelos, que necessitam de uma precisão superior.

Em alguns casos, foram utilizadas ferramentas para obter o tempo e a posição de pedestres e veículos marcados manualmente por um observador. Estes métodos foram denominados semiautomáticos. Entre as principais vantagens destes métodos estão a capacidade de visualizar e corrigir os eventos marcados e identificar a posição precisa dos objetos. Chae (2005) desenvolveu uma ferramenta semiautomática (ITRE semi-tracker), utilizada nos casos em que os objetos não puderam ser processados automaticamente. Esta ferramenta permitiu ao observador identificar um objeto, medir seu comprimento e marcar sua posição nas sucessivas imagens, extraindo dados no mesmo formato que a ferramenta principal.

Yang et al. (2006) desenvolveram uma ferramenta semiautomática mais simples. A medida de cada brecha, aceita ou rejeitada, foi obtida marcando 4 pontos na sequência de imagens: (i) a posição do pedestre, (ii) a posição de interseção das rotas do pedestre e do veículo, (iii) a posição do veículo e (iv) a posição do veículo depois de 0,25 segundos. Cada medição foi feita quando o veículo passou em frente ao pedestre. A filmagem, feita a partir do $27^{\circ}$ andar de um edifício, facilitou a identificação das posições, observadas praticamente do topo.

Uma parcela significativa dos estudos, no entanto, analisou vídeos sem auxílio de ferramentas de processamento de imagens. Entre eles, podemos destacar Lee e Lam (2008), Das et al. (2005), Sun et al. (2003), Schroeder (2008), Fitzpatrick et al. (2006) e Sisiopiku e Akin (2003). Em alguns casos especiais, autores utilizaram coletas complementares. Como exemplos, destacam-se Fitzpatrick et al. (2006), que utilizaram computadores de mão para coletar dados qualitativos sobre os pedestres e as travessias, e Schroeder (2008), que coletou a velocidade e posição dos veículos utilizando um radar laser (LIDAR).

Exemplificando a metodologia de trabalhos que extraíram dados manualmente, Lee e Lam (2008) transformaram vídeos em sequências de imagens, incluindo uma legenda com o tempo, e identificaram as imagens em que os pedestres iniciavam e terminavam a travessia. Das et al. (2005) extraíram um conjunto de informações mais amplo, com dois pesquisadores analisando os vídeos. Os pedestres foram caracterizados por sexo, faixa etária, situação (e.g. carregando bagagem), os tempos na chegada, início e conclusão da travessia e o sentido do deslocamento. Os veículos foram caracterizados pela posição do pedestre conflitante, se o veículo passa antes ou depois do pedestre, tipo de veículo, sentido de deslocamento, faixa de tráfego e os tempos da entrada e saída da travessia. A coleta foi utilizada para analisar as brechas aceitas por diferentes grupos de usuários e estimar modelos.

Na revisão dos processos de coleta de dados, foram identificadas diferentes metodologias que, geralmente, extraíram valores de brechas tradicionais ou variáveis para desenvolver novos modelos. A coleta de dados dos parâmetros brecha frontal e traseira, utilizados no VISSIM, não foi relatada. 


\section{METODOLOGIA}

Esta metodologia foi desenvolvida para obter valores de brechas frontais e traseiras de uma travessia não sinalizada. Esta seçãodescreve suas 4 etapas: (i) coleta das imagens, (ii) transformação das imagens, (iii) rastreamento dos objetos e (iv) processamento dos dados.

O uso de ferramentas para a extração semiautomática de dados das imagens foi adequado para a situação, especialmente porque (i) pedestres atravessavam fora do espaço reservado, apesar da existência de sinalização horizontal, (ii) aguardavam no espaço do veículo por uma brecha para atravessar e (iii) a faixa de tráfego do veículos era larga suficiente para a passagem de dois veículos, e os pedestres iniciavam a travessia antes da passagem de veículos que trafegavam no lado oposto. Para permitir a coleta de dados nestas situações, a área de conflito não foi associada à posição da sinalização horizontal. Foi considerada uma área de conflito ao longo da rota de cada pedestre, com a largura do veículo. Neste caso, brechas frontais e traseiras representam os valores mínimos aceitos pelo pedestre para qualquer travessia, e as brechas das três situações citadas são aproveitadas.

\subsection{Coleta das imagens}

A escolha do local de travessia é um aspecto crítico para obter maior precisão na posição dos pedestres e veículos. A coleta de dados foi realizada na interseção da Av. Getúlio Vargas com a Av. Ganzo, em Porto Alegre, no horário entre $11 \mathrm{~h} 00$ e $11 \mathrm{~h} 30$. A câmera foi posicionada no $9^{\circ}$ andar de um edifício próximo à interseção. A Figura 2 apresenta uma ilustração do local de travessia, onde pode-se observar a existência de um canteiro central e faixas de travessia de pedestres. A câmera foi posicionada a aproximadamente 30 metros de altura, a 25 metros da extremidade mais próxima da área de estudo.

Entre os principais critérios na escolha do local, destacam-se: existência de eventos de travessia suficientes para a análise, inexistência de congestionamentos, possibilidade de visualizar (sem barreiras visuais) o trajeto completo de pedestres e veículos, desde a aproximação até o final da tra- vessia, e a possibilidade de filmar a travessia vista de topo.

\subsection{Transformação das imagens}

As imagens capturadas são uma projeção perspectiva da área de estudos em um plano, que possui um sistema de coordenadas próprio, no qual as medidas e ângulos reais não são preservados. O objetivo desta etapa é aplicar uma transformação geométrica para obter a projeção das imagens no plano da área de estudos, possibilitando seu uso para o rastreamento. Neste estudo, com filmagens realizadas a partir uma sala comercial fechada, não houve necessidade de uma etapa de estabilização das imagens no processamento.

Existem casos em que a transformação é feita apenas nas coordenadas extraídas, após o rastreamento. Na metodologia proposta, as imagens são transformadas por dois motivos principais: (i) as posições, distâncias e velocidades reais dos objetos podem ser analisadas durante o rastreamento e (ii) os objetos mais distantes da posição da câmera, cujas dimensões são ampliadas com a transformação, são rastreados e têm seu contorno marcado com maior precisão.

A Figura 3 apresenta uma imagem original do vídeo (a), uma imagem após a transformação perspectiva (b) e uma resultante da sobreposição com uma imagem de satélite utilizada como referência das posições reais (c). A sobreposição das imagens permite identificar que a posição das sombras do caule das árvores do canteiro central (horizontais na imagem de referência) se encontra com a posição dos caules na imagem transformada, indicando uma transformação satisfatória. As faixas de pedestres sobrepostas corretamente e o alinhamento do meio-fio do canteiro central na parte inferior das imagens reforçam esta constatação.

Diversas ferramentas foram consideradas para fazer a transformação de imagens. Dentre as qualificadas, destacam-se as extensões (plug-ins) do software de domínio público chamado ImageJ, desenvolvido pelo National Institutes of Health (NIH, 2010). Algumas dificuldades em verificar a qualidade do ajuste e processar arquivos em lote, no entanto, resultaram no uso do software Matlab (Mathworks, 2010).

A transformação das imagens requer uma matriz que re-

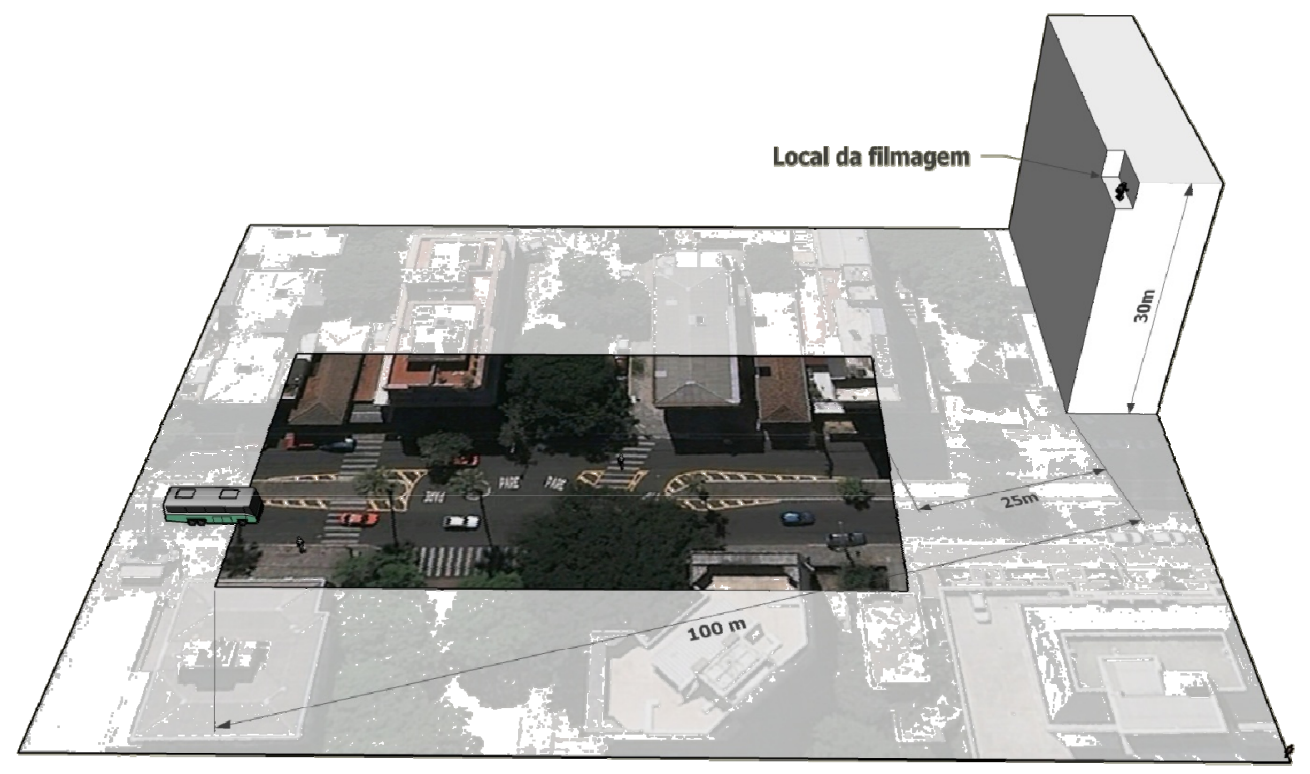

Figura 2. Local da filmagem e a área de estudo 


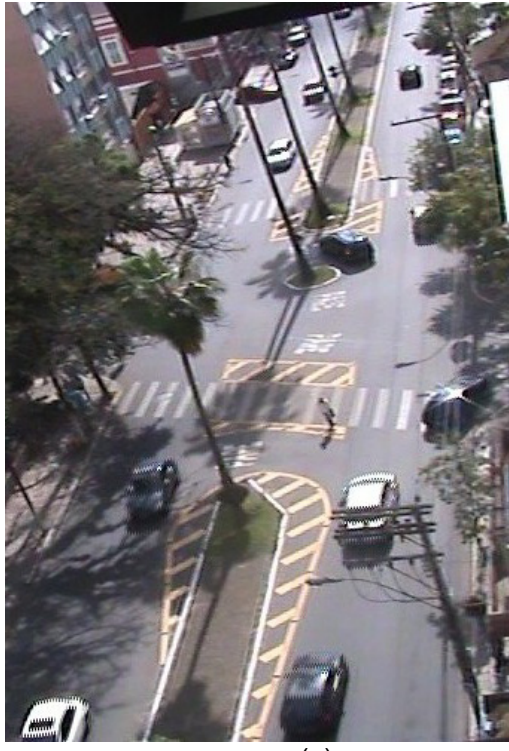

(a)

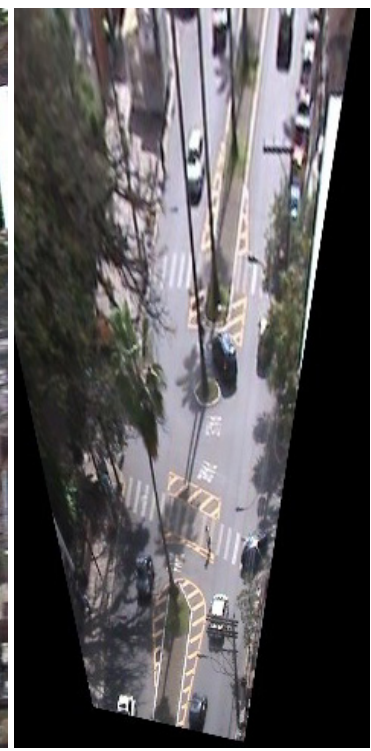

(b)

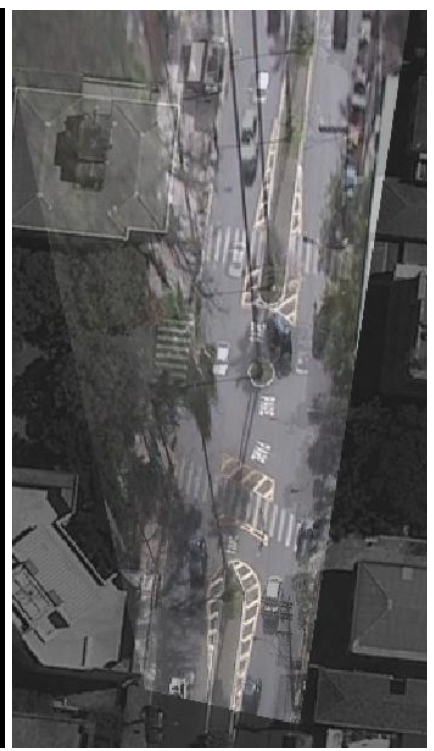

(c)

Figura 3. Imagens: original (a), transformada (b) e sobreposta com a imagem de referência (c)

lacione as coordenadas das imagens e as reais. A ferramenta de seleção de pontos de controle do Matlab foi utilizada para selecionar pontos na imagem original e nas posições correspondentes na imagem de satélite, usada como referência. Os pontos selecionados incluíram árvores, sinalização horizontal, postes, canteiros e esquinas. Foram necessários 4 pares de pontos para definir coeficientes da matriz, no entanto, foram selecionados mais pontos para reduzir o erro relacionado à precisão da marcação. As imagens foram transformadas com o próprio Matlab.

\subsection{Rastreamento dos objetos}

Esta etapa da metodologia é denominada rastreamento dos objetos porque os objetos (pedestres e veículos) são marcados ao longo da sequência de imagens de forma que resulte em uma rota. $\mathrm{O}$ rastreamento é feito por um observador, utilizando ferramentas específicas, que obedece a um conjunto de instruções para padronizar a coleta e facilitar o processamento. Apesar de o rastreamento ser uma tarefa simples, o tempo necessário para marcar a rota de cada objeto reforça a importância de uma ferramenta eficiente. O resultado desta etapa é uma tabela contendo o código do objeto, tempo (frame) e as coordenadas X e Y.

\subsubsection{Escolha da ferramenta de rastreamento}

As ferramentas desenvolvidas para coleta de dados de travessias em outros estudos não foram disponibilizadas. Como alternativa, foram identificadas ferramentas desenvolvidas para outras finalidades. Entre as extensões do programa ImageJ, as desenvolvidas para rastrear partículas manualmente em sequências de imagens puderam ser utilizadas diretamente. Neste artigo, foi selecionado o MTrackJ desenvolvido por Meijering (2010), do Biomedical Imaging Group Rotterdam. Esta ferramenta não permitiu marcar a dimensão dos veículos, portanto, neste procedimento foi usado o Matlab para desenhar um polígono no contorno de cada objeto.

As principais facilidades no uso do MTrackJ são a visualização da rota parcial com símbolos nos locais das marcações e a navegação entre as imagens com a roda do mouse (scroll wheel) ou atalhos de teclado. $\mathrm{O}$ arquivo de saída pode ser exportado como arquivo de texto, compatível com as ferramentas de processamento de dados.

\subsubsection{Instruções para rastreamento}

O procedimento de rastreamento dos objetos consiste em abrir uma sequência de imagens no aplicativo e marcar as posições de um objeto por vez. Elementos utilizados para orientar o rastreamento são apresentados na Figura 4a. As travessias foram analisadas separadamente em cada lado do canteiro, e foram identificadas na figura pelos números 1-3, pois barreiras visuais impediram a coleta na quarta travessia. A Figura 4a apresenta também o contorno das áreas de pedestres (amarelo), veículos (azul) e a interseção (rosa). A visualização do rastreamento no MTrackJ é ilustrado pela Figura $4 b$, que apresenta 3 rotas de veículos e uma de pedestre.

As instruções adotadas neste estudo foram:

1. as rotas de pedestres devem ter origem e destino em uma área de pedestres;

2. as rotas de veículos devem ter origem em uma área de veículos e destino na interseção;

3. os veículos que passam pela travessia quando não existem pedestres aguardando não devem ser marcados, exceto o último veículo antes da chegada de um pedestre;

4. uma rota de pedestre deve ser iniciada quando o pedestre chega ao local da travessia e aguarda uma oportunidade para atravessar, ou no instante anterior a entrar na via, caso não precise aguardar;

5. no caso de pedestres aguardando uma brecha, sua posição deve ser marcada no instante em que ele pára, aguardando a oportunidade de atravessar, e antes de completar o primeiro passo da travessia, de forma a obter precisamente o instante de início da travessia e o tempo de espera;

6. uma rota de pedestre deve ser finalizada quando ele chega à próxima área de pedestres, sendo contabilizado como um novo pedestre caso faça uma nova travessia; 


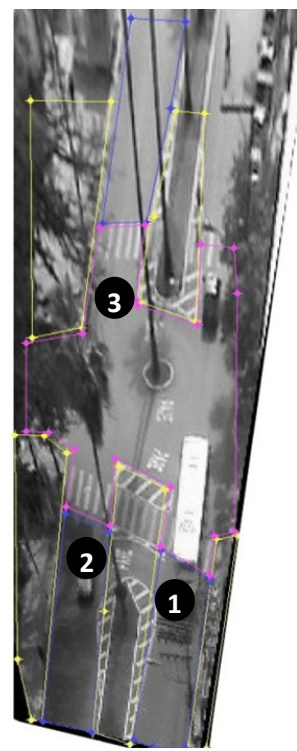

(a)

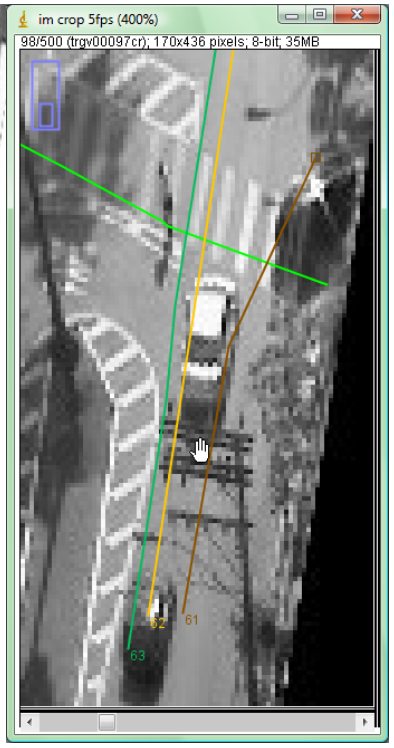

(b)

Figura 4. Elementos da área de estudo (a) e um exemplo de rastreamento com o MTrackJ (b)

7. a posição dos pedestres deve ser marcada no nível da interseção, sempre que possível no local dos pés, ou na projeção do tronco no chão;

8. uma rota de veículos deve ser iniciada quando o veículo aparecer completamente na imagem;

9. as posições dos objetos não devem ser marcadas em todas imagens da sequência, apenas nos pontos de origem e destino do deslocamento e pontos intermediários sempre que o objeto altera a sua velocidade ou direção;

10. para melhorar a precisão das rotas, posições intermediárias devem ser acrescentadas às rotas de veículos, especialmente nos anteriores e posteriores à travessia de pedestres;

11. a posição das motocicletas deve ser marcada no local referente à roda da frente; $\mathrm{e}$

12. a posição dos veículos deve ser marcada no lado esquerdo do para-choque dianteiro no sentido sulnorte (verticalmente para cima), no lado direito no sentido norte-sul.

\subsection{Processamento dos dados}

Esta etapa corresponde à análise das rotas para obter os valores de brechas frontais e traseiras. $\mathrm{O}$ processamento das rotas requer funções de geometria para analisar a relação espacial entre os objetos, que estão disponíveis no software Matlab. Esta seção apresenta as 4 etapas do processamento dos dados.

A primeira etapa corresponde à organização dos dados. Foi criada uma tabela, com uma linha para cada objeto, na qual foram computados o tempo inicial e final do objeto, a área de origem e destino, a distância percorrida, o tipo do objeto (pedestre, moto ou veículo) e uma última célula com valores múltiplos, com a sequência de coordenadas X, Y e o tempo dos pontos rastreados.

A segunda etapa corresponde ao cálculo das rotas de extremidades dos veículos que não foram rastreadas. No caso de veículos que foram rastreados a partir de um ponto localizado no lado esquerdo do para-choque dianteiro, por e- xemplo, as posições das outras três extremidades são calculadas. Nesta etapa são criadas colunas na célula com valores múltiplos de cada objeto, com as coordenadas $\mathrm{X}$ e $\mathrm{Y}$ de cada extremidade adicional dos veículos e motocicletas calculadas a partir das dimensões de um polígono ajustado ao contorno de cada objeto.

A terceira etapa corresponde à identificação dos valores das brechas frontais e traseiras. Para cada pedestre, são identificados os veículos e motocicletas que surgiram no intervalo entre 30 segundos antes do pedestre chegar à travessia, até 30 segundos após o pedestre concluir a travessia. Assumiu-se que veículos fora deste intervalo não influenciariam a travessia. A análise dos conflitos entre pedestres e veículos consiste em identificar a posição e o tempo em que ocorre o cruzamento entre suas rotas. Este procedimento utiliza funções do Matlab para identificar a interseção de polígonos, considerando as rotas como polígonos abertos. O tempo em que cada objeto passa pela interseção é obtido pela interpolação do tempo dos pontos anterior e posterior. No caso dos veículos, em que cada extremidade possui uma rota, é calculado um cruzamento para cada extremidade.

Os dados dos cruzamentos são armazenados em uma tabela de conflitos, que possui o código do pedestre e do veículo, um código da extremidade do veículo, o tempo em que o pedestre e veículo passam pelo ponto, as velocidades do pedestre e do veículo, a coordenada do ponto de cruzamento e o intervalo de tempo entre a passagem dos objetos (obtido subtraindo-se o tempo do pedestre do tempo do veículo). A brecha frontal do pedestre é o maior intervalo de tempo negativo (pois o tempo do pedestre é maior que o do veículo) e a brecha traseira é o menor intervalo de tempo positivo.

A quarta etapa corresponde à verificação dos resultados e eliminação das inconsistências. Nesta etapa foram verificados e corrigidos os casos em que as velocidades e rotas estavam fora do intervalo esperado. As brechas superiores a 5 segundos foram verificadas e eliminadas, assumindo que a influência do veículo na travessia destes casos não é significativa na análise das brechas mínimas aceitas pelos pedestres. Em alguns destes casos, observou-se que o veículo já 
não estava no campo de visão do pedestre.

\section{RESULTADOS E DISCUSSÃO}

Os principais resultados da coleta de dados são os valores das brechas frontais e traseiras, apresentados neste capítulo. Foram rastreados 147 pedestres e 508 veículos no total, sendo 17 motocicletas. No período de coleta de dados, todos os pedestres observados tiveram brechas frontais e traseiras medidas. No entanto, é importante ressaltar que nas situações em que os veículos deram preferência a grupos de pedestres na travessia, o comportamento dos pedestres não corresponde ao de aceitação de brechas representado pelos modelos de simulação. Por este motivo, 40 pedestres rastreados não foram incluídos na análise a seguir.

Em outras situações os pedestres atravessaram em brechas longas, provocadas pelos semáforos adjacentes às interseções. Os pedestres que chegavam à travessia durante estas brechas atravessavam imediatamente, com brechas frontais superiores a 5 segundos. Outros pedestres, que já estavam aguardando junto à travessia, atravessavam com brechas traseiras muito superiores a 5 segundos, pois o veículo seguinte ainda estava distante. Estes casos foram desconsiderados na análise a seguir, que teve o objetivo de ilustrar especialmente as situações em que as brechas frontais e traseiras estavam mais próximas do limite mínimo aceito pelos pedestres.

As brechas frontais e traseiras coletadas neste estudo são representadas por distribuições de frequências, em forma de histogramas. No histograma de brechas frontais da Figura 5 , observa-se que a maioria dos pedestres atravessou com brechas entre 0,5 e 2,5 segundos, apesar de que existe uma concentração de pedestres que aceitam brechas entre 1 e 2 segundos. Ajustando os dados a distribuições de probabili- dades com o software EasyFit (Mathwave, 2010), verificou-se que a distribuição Log-logística representou razoavelmente bem aos valores medidos. A Figura 5 apresenta também a distribuição de frequências acumulada e a distribuição Log-logística. A média das brechas frontais aceitas é 2,21 segundos e em $75 \%$ dos casos observados o valor foi inferior a 2,5 segundos.

A Figura 6 apresenta o histograma das brechas traseiras, além da distribuição acumulada e da distribuição de probabilidades Gama, que apresentou um ajuste razoável aos valores observados. Observa-se que um percentual pequeno dos pedestres aceita brechas traseiras inferiores a 1,5 segundos $(10 \%)$, diferentemente do observado com as brechas dianteiras. A dispersão significativamente maior nos valores de brechas traseiras é decorrente da distribuição da chegada dos veículos e, principalmente, da percepção do pedestre sobre o tempo necessário para atravessar com segurança. A média observada é 2,6 segundos, sendo que em $75 \%$ dos casos é inferior a 3,5 segundos.

A análise das brechas aceitas pelos pedestres indica que as brechas traseiras aceitas pelos pedestres são superiores às frontais. Apesar do valor recomendado pelo VISSIM (PTV, 2009) para ambos os parâmetros ser 0,5 segundos, obervou-se que na prática poucos pedestres aceitaram brechas frontais e traseiras inferiores a 1 segundo.

A análise preliminar da distribuição de brechas frontais e traseiras aceitas pelos pedestres na travessia não evidencia quais os valores dos parâmetros que devem ser utilizados no modelo de simulação para reproduzir o comportamento observado. A dificuldade em obter o valor deste parâmetro diretamente a partir de observações de campo decorre da variabilidade nos comportamentos obervados nas travessias. Esta variabilidade é decorrente de diversos fatores que

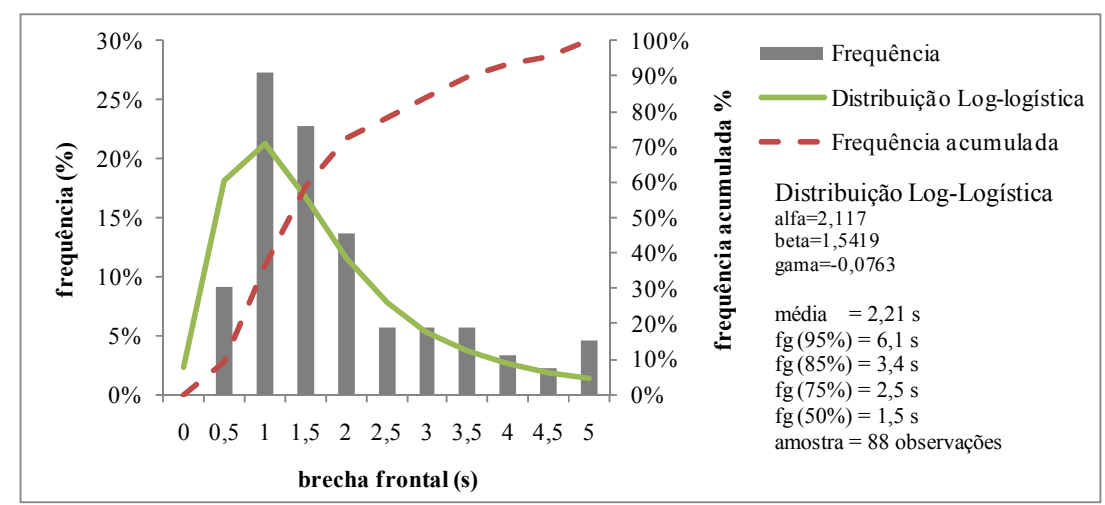

Figura 5. Histograma de brechas frontais e ajuste com a distribuição Log-logística

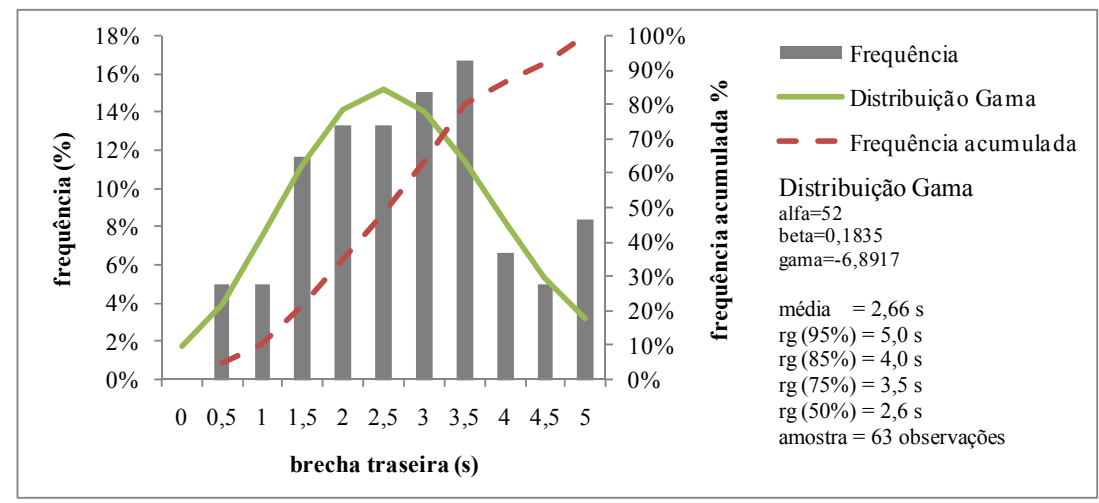

Figura 6. Histograma de brechas traseiras e ajuste com a distribuição Gama 
influenciam a decisão dos pedestres, que incluem desde características físicas do ambiente, como a geometria viária, até características do tráfego de pedestres e veículos, como volume, regime de chegada e velocidades que variam ao longo do tempo, e diferenças na percepção de segurança.

Considerando a complexidade dos comportamentos nas travessias, o processo de calibração dos modelos é fundamental. Neste processo, além dos valores de brechas frontais e traseiras aceitas pelos pedestres, é importante considerar as condições de tráfego, como por exemplo, a distribuição de chegada dos veículos à travessia. A confiabilidade dos resultados de modelos envolvendo pedestres deve exigir uma associação mais criteriosa entre os valores adotados para parâmetros e as condições simuladas, do que normalmente praticado em simulações convencionais de veículos.

Estas características do comportamento em travessias e do processo de calibração de modelos impõem um maior desafio para o desenvolvimento de estudos multimodais, nos quais tempos de viagem e atrasos do modo a pé são importantes elementos de avaliação.

\section{CONSIDERAÇÕES FINAIS}

Este artigo apresentou a metodologia de coleta de dados utilizada na extração de dados para a calibração do modelo de aceitação de brechas do VISSIM e análise dos resultados. Algumas técnicas propostas, como a transformação das imagens antes da extração dos dados e a análise espacial do conflito entre as rotas não constam na literatura, mas apresentam vantagens em relação aos métodos manuais frequentemente utilizados.

Os parâmetros brecha frontal e traseira são medidos em relação à área de travessia, e não entre os veículos como no caso do modelo de aceitação de brechas tradicional. Neste caso, a metodologia proposta possui flexibilidade para analisar as brechas no local do conflito, mesmo fora da área sinalizada, viabilizando a coleta destas variáveis compatíveis com as observadas frequentemente em cidades brasileiras.

No processamento de dados deste artigo, outras informações poderiam ter sido obtidas a partir das rotas, como as distribuições de chegadas de veículos e pedestres, velocidades e atrasos. Entre outras variáveis, o número de pedestres na área de espera quando o veículo se aproxima, poderia ser utilizado em modelos que representem a decisão do motorista sobre dar preferência aos pedestres em travessias. Considerando as inovações da metodologia proposta, a utilização apenas de ferramentas acessíveis (filmadora, softwares de domínio público e comerciais) e a flexibilidade para ser utilizada em diferentes situações, constata-se que existe potencial para o seu uso em coletas de dados de diversas configurações de travessias e interseções.

\section{AGRADECIMENTOS}

Os autores agradecem o apoio concedido pelo CNPq e CAPES através de bolsas de produtividade de pesquisa e mestrado e apoio financeiro ao projeto.

\section{REFERÊNCIAS BIBLIOGRÁFICAS}

Blue, V. e J. Adler (1999) Cellular automata microsimulation of bidirectional pedestrian flows, Research Board $78^{\text {nd }}$ Annual Meeting, Washington D.C., CD-ROM.

Chae, K. (2005) Simulation of pedestrian-vehicle interactions at roundabouts. Tese (doutorado), North Carolina State University, Raleigh.

Chu, X.; M. Guttenplan e M. Baltes (2004) Why people cross where they do: the role of the street environment. Transportation Research Record, v. 1878, p. 3-10.

Das, S.; C.F. Maski e M.D. Manuszak (2005) Walk or wait? An empirical analysis of street crossing decisions. Journal of Applied Econometrics, v. 20, p. 529-548.

Fitzpatrick, K.; S.M. Turner; M.A. Brewer; P.J. Carlson; N. Lalani; B.R. Ullman; N.D. Trout; E. Park; D. Lord e J.A. Whitacre (2006) Improving Pedestrian Safety at Unsignalized Crossings. NCHRP Report. 562. Transportation Research Board.

Ismail, K.; T. Sayed; N. Saunier e C. Lim (2009) Automated analysis of pedestrian-vehicle conflicts using video data. Transportation Research Board $88^{\text {nd }}$ Annual Meeting, Washington D.C., CD-ROM.

Lee, J.Y.S. e W.H.K. Lam (2008) Simulating pedestrian movements at signalized crosswalks in Hong Kong. Transportation Research Part $A$, v. 42, p. 1314-1325.

Mathwave (2010) EasyFit Professional Edition.

Mathworks (2010) Matlab v.R2010a.

Meijering, E. (2010) MTrackJ: A Java Program for Manual Object Tracking. Disponível em: <http://www.imagescience.org/meijering/ software/mtrackj/> (Acesso em 24/10/2010).

NIH (2010) Image Processing and Analysis in Java. Disponível em: $<$ http://rsbweb.nih.gov/ij/> (Acesso em 24/10/2010).

PTV (2009) VISSIM 5.20 User Manual.

Schmidt, S. e B. Färber (2009) Pedestrians at the kerb - Recognising the action intentions of humans. Transportation Research Part F, v. 12 , p. 300-310.

Schroeder, B.J. (2008) A Behavior-Based Methodology for Evaluating Pedestrian-Vehicle Interaction at Crosswalks. Tese (Doutorado), North Carolina State University, Raleigh .

Sisiopiku, V.P. e D. Akin (2003) Pedestrian behaviors at and perceptions towards various pedestrian facilities: an examination based on observation and survey data. Transportation Research Part F, v. 6, p. $249-274$.

Sun, D.; S.V. Ukkusuri; R.F. Benekohal e S.T. Waller (2003) Modeling of motorist-pedestrian interaction at uncontrolled mid-block crosswalks. Transportation Research Board $82^{\text {nd }}$ Annual Meeting, Washington D.C.

TRB (2000) Highway Capacity Manual. Transportation Research Board. Special Report 209.National Research Council, Washington, DC, EUA, $4^{\mathrm{a}}$ ed.

Yang, J.; W. Deng; J. Wang; Q. Li e Z. Wang (2006) Modeling pedestrians' road crossing behavior in traffic system micro-simulation in China. Transportation Research Part A, v. 40, p. 280-290. 